\title{
Management of Peritoneal Carcinomatosis With Cytoreductive Surgery Combined With Intraperitoneal Chemohyperthermia at a Novel Italian Center
}

\author{
PINUCCIA FAVIANA ${ }^{1}$, LAURA BOLDRINI ${ }^{1}$, BARBARA MUSCO ${ }^{2}$, MAURO FERRARI $^{2}$, ALFONSO GRECO $^{2}$, \\ LORENZO FORNARO ${ }^{3}$, GIANLUCA MASI ${ }^{3}$, FRANCESCO FORFORI $^{1}$, SERGIO RICCI $^{3}$, AUGUSTO BROGI $^{1}$, \\ FULVIO BASOLO $^{1}$, ALFREDO FALCONE ${ }^{3}$, ANGELO GADDUCCI ${ }^{4}$ and PIERO VINCENZO LIPPOLIS ${ }^{2}$ \\ ${ }^{1}$ Department of Surgical, Medical, Molecular Pathology and Critical Care, University of Pisa, Pisa, Italy; \\ ${ }^{2}$ Department of General Surgery, Azienda Ospedaliera Universitaria Pisana, Pisa, Italy; \\ ${ }^{3}$ Department of Translational Research and New Technologies in Medicine and Surgery, \\ University of Pisa, Pisa, Italy; \\ ${ }^{4}$ Department of Clinical and Experimental Medicine, University of Pisa, Pisa, Italy
}

\begin{abstract}
Background: Peritoneal carcinomatosis (PC) is a common manifestation of many gastrointestinal (GI) malignancies and is an advanced stage that is often associated with disseminated disease. Considerable progress has been made to achieve safe elimination of macroscopic disease using cytoreductive surgery $(C R S)$ and more recently in combination with hyperthermic intraperitoneal chemotherapy (HIPEC) for the treatment of microscopic disease or disease with minimal volume. The aim of this study was to assess the effects of such procedures on the quality of life (QoL), the long-term benefit and the functional status of the treated patients. Patients and Methods: Data from patients who underwent CRS-HIPEC for peritoneal metastasis (PM) at our center from November 2016 to November 2018 were analyzed retrospectively. The drugs administered were mitomycin and cisplatin. Quality of life (QoL) was assessed using the Euroquol-5D-5L and National Comprehensive Cancer Network Functional Assessment of Cancer Therapy-Breast Cancer Symptom Index v2 questionnaires before CRS-HIPEC, and 1, 3 and 6 months after were administered. Results: In our series, the survival efficacy of CRS plus HIPEC was confirmed in the treatment of primary and secondary peritoneal pathologies, particularly in ovarian cancer, although larger studies are
\end{abstract}

This article is freely accessible online.

Correspondence to: Dott.ssa Pinuccia Faviana, Department of Surgical, Medical, Molecular Pathology and Critical Area, University of Pisa, Via Roma 57, 56126 Pisa, Italy. Tel: +39 050992991, Fax: +39050996715, e-mail: pinuccia.faviana@med.unipi.it

Key Words: HIPEC, gastric cancer, colon cancer, ovary cancer. needed to investigate its role in the pathology of gastric, colonic and rectal cancer. The QoL data were promising, with essentially stable values between the preoperative and the 1-month follow-up, but with incremental benefits from the second to the third month.

Peritoneal carcinomatosis (PC) is a common manifestation of many gastrointestinal (GI) malignancies and is an advanced stage of abdominal cancer that is often associated with disseminated disease. $\mathrm{PC}$ is the epitome of a progressive malignant and recurring disease. A poor prognosis for overall survival (OS) and poor quality of life (QoL) has typically been found, which is of paramount importance in cancer treatment (1). During the period between 1987 and 1993, Sugarbaker et aI. repeatedly reported favorable results for the efficacy of cytoreductive surgery (CRS) and hyperthermic intraperitoneal chemotherapy (HIPEC) for patients with peritoneal pseudomyxoma $(2,3)$. Since then, the technique has been used with promising results in patients diagnosed with PC of from ovarian, gastric, colic and appendicular origin, and in malignant peritoneal mesothelioma (4). Many mechanisms of peritoneal spread have been proposed (5-8) including invasion of the lumen wall by invasive cancer, expression of adherence molecules by free cancer cells can support peritoneal implantation (5), and iatrogenic spread during surgery. If left untreated, peritoneal cancer quickly develops into malignant ascites, acute intestinal obstruction and perforation, which require aggressive palliative chemotherapy or debulking surgery. The incidence of peritoneal metastases is often underestimated due to the low sensitivity rate of conventional imaging techniques for peritoneal diseases (9). The rate of sensitivity of computed tomography when identifying peritoneal disease depends on the location in the abdominal 


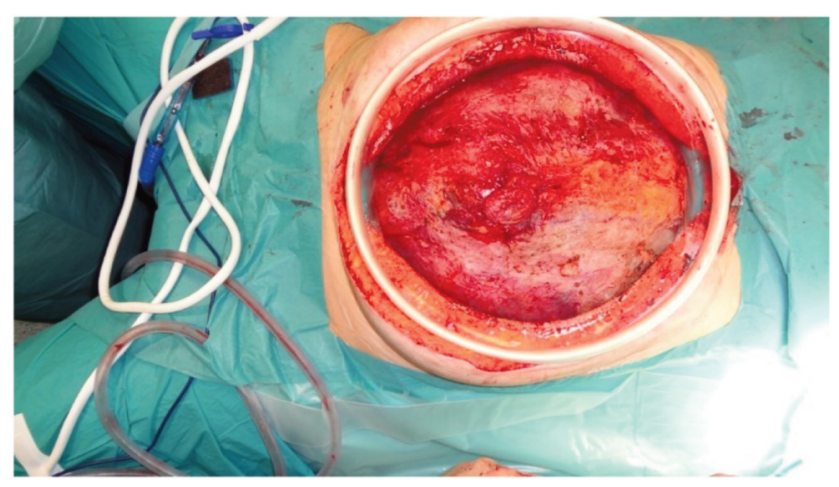

Figure 1. Median laparotomy without incision of the parietal peritoneum in a case of pseudomyxoma peritonei (female, 69 years old). Total peritonectomy with right hemicolectomy extended to middle transverse, distal splenopancreatectomy, left hysteroannectectomy, cholecystectomy, positioning of double ureteral stent.

cavity, the size of the individual nodes and the morphology of the disease. Conventional anti-neoplastic strategies for visceral metastases are not effective in peritoneal carcinomas, since the lower survival rate in patients with peritoneal carcinoma indicates an inherently unfavorable biology (10). The management and therapy of this clinical entity, which strike a balance between efforts to prolong survival and improve quality of life, are challenging and have evolved significantly over the past century. Considerable progress has been made in safely eliminating macroscopic disease using CRS and more recently in combination with HIPEC to treat microscopic or minimal volume disorders. CRS plus HIPEC improves survival and quality of life in patients with peritoneal metastases $(11,12)$. Multimodal management is based on the concept of the peritoneum as an organ and assumes that an improved prognosis will be achieved if the disease is completely dependent on it.

The aim of this study was to assess the effects and procedures on the quality of life, long-term benefits and functional status of the treated patients.

\section{Patients and Methods}

The data of the 70 patients who underwent CRS-HIPEC for peritoneal metastases at our center from November 2016 to November 2018 were analyzed retrospectively. The drugs administered were mitomycin and cisplatin. QoL was assessed using the Euroquol-5D-5L and National Comprehensive Cancer Network Functional Assessment of Cancer Therapy-Breast Cancer Symptom Index v2 questionnaires administered before CRS-HIPEC, and at 1, 3 and 6 months after. Survival analyses were carried out on 50 patients affected by gastric carcinoma and colorectal carcinoma after first-line chemotherapy, and ovarian cancer after primary and postoperative chemotherapy using the Kaplan-Meier method using GraphPad $^{\circledR}$ software v8.0 (San Diego, CA, USA). The patients were

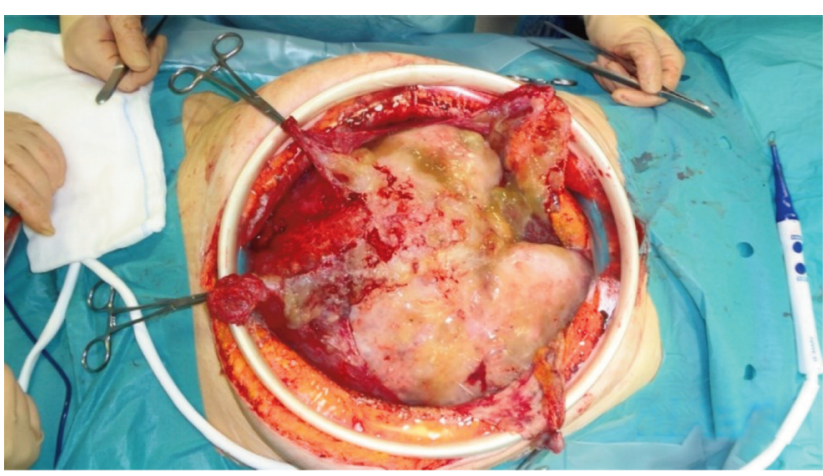

Figure 2. Opening of the peritoneum: peritoneal cavity occupied by voluminous mucinous mass in a case of pseudomyxoma peritonei.

examined with routine blood tests, liver function tests and coagulation studies before surgery. Abdominal and pelvic $\left[{ }^{18} \mathrm{~F}\right]-$ fluorodeoxyglucose-positron-emission tomography imaging was performed for most patients. All cases were discussed at the multidisciplinary peritoneal disease meeting, which was attended by peritoneal surgeons, oncologists, pathologists and radiologists. All patients have signed an informed consent.

Diagnosis and treatment. The cancer entities included were defined as follows: Pseudomyxoma peritonei as a clinical disease caused by cancer cells that produce slimy, gelatinous ascites that result from slimy neoplasms of the appendix (low-grade or highgrade mucous neoplasms); peritoneal metastases of the ovaries as those due to high-grade papillary serous carcinoma; colorectal peritoneal metastases as those due to colorectal adenocarcinoma; and gastric peritoneal metastases as those resulting from gastric adenocarcinoma. The average peritoneal cancer index (PCI) was 9.7 (range=1-24).

CRS was carried out according to the Sugarbaker technique (12). Organ resections included segmental colectomy, peritonectomy, small bowel resection, cholecystectomy, splenectomy, partial and only rarely complete gastrectomy, liver segment resection and, in women, hysterectomy with bilateral salpingo-oopherectomy. When metastatic nodules were present on an organ surface, these were resected until an R0/CC 0 resection was obtained.

Nodes on the small intestinal serosa were removed with primary occlusion, but when there were a large number of nodes on the same small intestinal segment, resection was performed. Nodules on the colonic serosa required segmental colectomy. Similarly, splenectomy was performed for nodules on the spleen. In the case of nodules on the stomach, they were generally excised with a primarily closed defect but, as with small intestinal segments, when a large number of nodules were present, a formal partial or full gastrectomy was performed.

The removal of the pelvic and diaphragmatic peritoneum was recorded when performed (Figures 1 and 2). The extent of cytoreduction (CC) was recorded at the end of each operation: $\mathrm{CC}$ 0: no macroscopic residual disease remained; $\mathrm{CC} 1,2$ and 3: residual disease of $<2.5 \mathrm{~mm}, 2.5 \mathrm{~mm}$ to $2.5 \mathrm{~cm}$ or $>2.5 \mathrm{~cm}$, respectively. A CC of $0 / 1$ was viewed macroscopically as a complete resection and was followed by HIPEC. Cases with CC 2 and 3 were considered incomplete cytoreduction and the HIPEC 
Table I. General characteristics of patients $(N=70)$.

\begin{tabular}{llc}
\hline Variable & & Value \\
\hline Age, years & Mean (range) & $60.24(35-77)$ \\
Gender, n (\%) & Male & $16(23 \%)$ \\
& Female & $54(77 \%)$ \\
Primary tumor, & Ovarian & $37(53 \%)$ \\
n $(\%)$ & Colorectal & $18(26 \%)$ \\
& Gastric & $10(14 \%)$ \\
& Peritoneal & $4(6 \%)$ \\
& Mesothelioma (appendix) & $1(1 \%)$ \\
\hline
\end{tabular}

Table II. Intraoperative findings of patients $(N=70)$.

\begin{tabular}{llc}
\hline Variable & & Value \\
\hline CC Score (\%): & 0 & $63(90 \%)$ \\
& 1 & $5(7 \%)$ \\
& 2 & $2(3 \%)$ \\
Reason for & Miliary pattern disease & $5(7 \%)$ \\
CC score $>0, n(\%)$ & Diffuse infiltration of pancreas & $1(1 \%)$ \\
& Infiltration of hepatic pedicle & $1(1 \%)$ \\
PCI & Mean (range) & $9.6(0-24)$ \\
HIPEC agent, n (\%) & Cisplatinum & $40(57 \%)$ \\
& Mitomycin & $30(43 \%)$ \\
\end{tabular}

C-C Score: Completeness of cytoreduction; PCI: peritoneal cancer index; HIPEC: hyperthermic intraperitoneal chemotherapy.

procedure was not used, except in selected cases such as the presence of difficult to treat ascites. HIPEC was carried out as a 'closed' technique (via an open coliseum) with an intraperitoneal target temperature of $41-43^{\circ} \mathrm{C}$.

HIPEC drugs and dosage. Details of treatment for each malignancy were the following: Pseudomyxoma peritonei: Intraperitoneal (i.p.) mitomycin-C at $15 \mathrm{mg} / \mathrm{m}^{2}$ with intravenous (i.v.) 5 -fluorouracil at (5-FU) at $400 \mathrm{mg} / \mathrm{m}^{2}$ for $90 \mathrm{~min}$; mesothelioma: i.p. cisplatin at 100 $\mathrm{mg} / \mathrm{m}^{2}$ with mitomycin-C at $12.5 \mathrm{mg} / \mathrm{m}^{2}$ for $90 \mathrm{~min}$; colorectal peritoneal metastases: i.p. oxaliplatin at $350 \mathrm{mg} / \mathrm{m}^{2}$ with i.v. $5-\mathrm{FU}$ at $400 \mathrm{mg} / \mathrm{m}^{2}$ for $30 \mathrm{~min}$ (in cases of known resistance to previous systemic i.v. oxaliplatin, mitomycin-C at $15 \mathrm{mg} / \mathrm{m}^{2}$ for $90 \mathrm{~min}$ was administered); gastric cancer: i.p. cisplatin at $50 \mathrm{mg} / \mathrm{m}^{2}$, doxorubicin at $15 \mathrm{mg} / \mathrm{m}^{2}$ with i.v. $5-\mathrm{FU}$ at $400 \mathrm{mg} / \mathrm{m}^{2}$ for $60 \mathrm{~min}$; ovarian cancer: i.p. cisplatin at $100 \mathrm{mg} / \mathrm{m}^{2}$ with i.v. 5 -FU at $400 \mathrm{mg} / \mathrm{m}^{2}$ for $60 \mathrm{~min}$.

\section{Results}

At our center, 70 patients, 16 men and 54 women, between the ages of 35 and 77 (average age $=60$ years) were examined. The origin of the peritoneal disease was ovarian and colorectal cancer in the majority of cases (79\%) (Table I).

Complete cytoreduction was achieved in 63 patients $(90 \%$ $\mathrm{CC}$ 0). The average PCI was 9.6 (range $=0-24)$ (Table II).
Table III. Postoperative outcomes $(N=70)$.

\begin{tabular}{|c|c|c|}
\hline & Type (Clavien-Dindo grade) & \\
\hline $\begin{array}{l}\text { Morbidity rate, } \\
\mathrm{n}(\%)\end{array}$ & 30-Day & $23(33 \%)$ \\
\hline \multirow{14}{*}{$\begin{array}{l}\text { Type of } \\
\text { complication, } \\
\mathrm{n}(\%)\end{array}$} & Mild renal failure (I) & $3 / 23(14 \%)$ \\
\hline & Diarrhea (I) & $1 / 23(4 \%)$ \\
\hline & $\begin{array}{l}\text { Upper limb sensory-motor } \\
\text { deficit (II) }\end{array}$ & $1 / 23(4 \%)$ \\
\hline & Pulmonary infection (II) & $1 / 23(4 \%)$ \\
\hline & Pulmonary embolism (II) & $2 / 23(9 \%)$ \\
\hline & Anemia (II) & $1 / 23(4 \%)$ \\
\hline & Superficial vein thrombosis (II) & $2 / 23(9 \%)$ \\
\hline & Grade A pancreatic fistula (II) & $1 / 23(4 \%)$ \\
\hline & Bowel sub-occlusion (II) & $1 / 23(4 \%)$ \\
\hline & Pleural effusion with drainage (IIIa) & $2 / 23(9 \%)$ \\
\hline & Intestinal anastomosis dehiscence (IIIb) & $4 / 23(18 \%)$ \\
\hline & Intra-abdominal hemorrhage (IIIb) & $2 / 23(9 \%)$ \\
\hline & Respiratory failure (IVa) & $1 / 23(4 \%)$ \\
\hline & $\begin{array}{l}\text { Multiple organ dysfunction syndrome } \\
\text { (IVb) }\end{array}$ & $1 / 23(4 \%)$ \\
\hline \multirow{4}{*}{$\begin{array}{l}\text { Major } \\
\text { complication, } \\
\mathrm{n}(\%)\end{array}$} & IIIa & $2 / 23(9 \%)$ \\
\hline & $\mathrm{IIIb}$ & $6 / 23(27 \%)$ \\
\hline & IVa & $1 / 23(4 \%)$ \\
\hline & $\mathrm{IVb}$ & $1 / 23(4 \%)$ \\
\hline $\begin{array}{l}\text { Mortality rate, } \\
\mathrm{n}(\%)\end{array}$ & 30-Day & $0 / 70(0 \%)$ \\
\hline $\begin{array}{l}\text { Hospitalization, } \\
\text { days }\end{array}$ & Mean (range) & $14.4(9-41)$ \\
\hline
\end{tabular}

In 19 patients ( $27 \%$ of all patients) with ovarian cancer, the median progression-free survival was 12.2 months. In 14 patients $(20 \%)$ with colorectal cancer, the median diseasefree survival was 9.3 months and the median overall survival was 14.8 months. In seven patients (10\%) with gastric cancer, we found a median progression-free survival of 5.2 months and an overall survival of 7.7 months.

Of the four patients affected by primary peritoneal disease, three were free of disease after 6 months and only one after 30 months.

The overall 30-day morbidity rate was $33 \%$ (23 out of 70 patients). The frequency of postoperative complications is used as an indicator of surgical quality. However, the comparison of the results is hampered by a lack of agreement in defining the complications and their severity. The Clavien-Dindo classification is a standardized system for the registration of surgical complications. The main feature of the Clavien-Dindo system is that the severity of a complication is assessed based on the type of therapy required to treat the complication. The CDC system has been validated and accepted worldwide for use in many areas of surgery. The complication rate was $10 \%$ in the late postoperative period (6-8 months). The average hospitalization was 14 days (range $=9-41$ days) and no perioperative mortality was registered (Table III). 
The questionnaires for the follow-up were completed by $100 \%$ of the patients immediately before therapy, and by $95 \%, 91 \%$ and $59 \%$ at 1,3 and 6 months after therapy, respectively. Average 'health perception' was reported by $51 \%$ before therapy, and by $53 \%, 67 \%$ and $75 \%$ of patients at 1, 3 and 6 months after therapy. An average 'degree of anxiety' was reported by $86 \%, 80 \%, 65 \%$ and $61 \%$ of patients, respectively. An average 'pain intensity' was given by $57 \%, 52 \%, 35 \%$ and $30 \%$.

\section{Discussion}

Surgery CRS with peritonectomy procedures and multivisceral resection and the subsequent administration of HIPEC can achieve better overall survival results, especially in selected patients. Currently, CRS with HIPEC can be considered the gold standard treatment for patients with pseudomyxoma peritonei, and even more so for patients with malignant peritoneal mesothelioma $(13,14)$. In addition, HIPEC treatment after aggressive CRS is safe in terms of morbidity in centers with extensive experience (15-18). The use of CRS with HIPEC in patients with peritoneal neoplasms is widespread worldwide and has given an increasing number of patients access to multidisciplinary treatment programs for PC $(12,19,20)$.

The aim of this study was to evaluate the effectiveness of this treatment and survival in patients with peritoneal metastasis of ovarian, colon and gastric cancer after cytoreduction intervention with HIPEC. The benefits of CRS and HIPEC are supported by international consensus guidelines, such as the American Society of Colon and Rectal Surgeons (21) and the European Society of Medical Oncology (22). Peritoneal service in our center has been active since 2016 and has increased in recent years. This is further evidence of the overall greater acceptance of the growing role of CRS and HIPEC in the treatment of peritoneal tumors in the oncological community. CRS and HIPEC are effective but on the other hand do have significant morbidity. Grade III/IV complications occurred in $33 \%$ of our cases and perioperative mortality in the cohort was $2 \%$. These results are comparable to larger volume studies with reported morbidity and mortality rates of $28.8 \%$ to $60 \%$ and $2.9 \%$ to $8.3 \%(20,23-26)$. The recent PRODIGE 7 study on peritoneal carcinomatosis from colorectal cancer also showed grade III/IV complication rates of $40.6 \%$ and $31.1 \%$ in the HIPEC and non-HIPEC groups, respectively (18). Grade IIIb complications were associated with higher PCI scores. In our study, high-grade complications were also associated with higher PCI values, confirming that adequate patient selection is the key to maximizing the benefit while minimizing the risks of the procedure.

A number of prognostic factors have been found to be related to overall survival. CC score, PCI, positive lymph nodes, histology, use of systemic perioperative chemotherapy and the experience of the center proved to be prognostic factors that influence overall survival $(20,27-30)$.

In our series, the survival efficacy of CRS with HIPEC was confirmed in the treatment of primary and secondary peritoneal pathologies, particularly in ovarian cancer, although larger studies are needed to investigate its role in the pathology of gastric, colonic and rectal primary cancer.

The QoL data are promising, with essentially stable values between the preoperative and the 1-month follow-up, but with incremental benefits from the second assessment to the third. Treatment with CRS plus HIPEC can achieve a longterm benefit that has a positive effect on pain control, on the level of anxiety and generally on improving the perception of health status.

These results show that CRS plus HIPEC can be performed at a new specialized center with morbidity and mortality rates that match those of other major centers.

\section{Conflicts of Interest}

All Authors approved the article for submission and they had no conflicts of interest to declare.

\section{Authors' Contributions}

Study concepts: P. Faviana, P. V. Lippolis, I. V. Boldrini; Study design: P. Faviana, P. V. Lippolis; Data acquisition: B. Musco, A. Greco, M. Ferrari, L. Fornaro, G. Masi; Quality control of data and algorithms: F. Forfori, A. Brogi; Data analysis and interpretation: S. Ricci, A. Gadduci; Statistical analysis: P. V. Lippolis, I. V. Boldrini; Manuscript preparation: P. Faviana, P. V. Lippolis; Manuscript editing: F. Forfori, A. Falcone, F. Basolo; Manuscript review: P. Faviana, I. V. Boldrini, P. V. Lippolis.

\section{References}

1 Spiliotis J, Halkia E and de Bree E: Treatment of peritoneal surface malignancies with hyperthermic intraperitoneal chemotherapy-current perspectives. Curr Oncol 23(3): e266-z75, 2016. PMID: 27330364. DOI: 10.3747/co.23.2831

2 Sugarbaker PH, Kern K and Lack E: Malignant pseudomyxoma peritonei of colonic origin. Natural history and presentation of a curative approach to treatment. Dis Colon Rectum 30(10): 772779, 1987. PMID: 2820671. DOI: 10.1007/bf02554625

3 Sugarbaker PH, Zhu BW, Sese GB and Shmookler B: Peritoneal carcinomatosis from appendiceal cancer: results in 69 patients treated by cytoreductive surgery and intraperitoneal chemotherapy. Dis Colon Rectum 36(4): 323-329, 1993. PMID: 8458256. DOI: 10.1007/bf02053933

4 Kulu Y, Muller-Stich B, Buchler MW and Ulrich A: Surgical treatment of peritoneal carcinomatosis: current treatment modalities. Langenbecks Arch Surg 399(1): 41-53, 2014. PMID: 24249036. DOI: $10.1007 / \mathrm{s} 00423-013-1144-8$

5 Sugarbaker PH: Observations concerning cancer spread within the peritoneal cavity and concepts supporting an ordered pathophysiology. Cancer Treat Res 82: 79-100, 1996. PMID: 884994. DOI: 10.1007/978-1-4613-1247-5_6 
6 Coccolini F, Gheza F, Lotti M, Virzì S, Iusco D, Ghermandi C, Melotti R, Baiocchi G, Giulini SM, Ansaloni L and Catena F: Peritoneal carcinomatosis. World J Gastroenterol 19(41): 69796994, 2013. PMID: 24222942. DOI: 10.3748/wjg.v19.i41.6979

7 Shariat-Madar B1, Jayakrishnan TT, Gamblin TC and Turaga KK: J Surg Oncol 110(6): 666-669, 2014. PMID: 24986323. DOI: $10.1002 /$ jso. 23707

8 Klaver YL, Lemmens VE, Creemers GJ, Rutten HJ, Nienhuijs SW and de Hingh IH: Population-based survival of patients with peritoneal carcinomatosis from colorectal origin in the era of increasing use of palliative chemotherapy. Ann Oncol 22(10): 22502256, 2011. PMID: 21345939. DOI: 10.1093/annonc/mdq762

9 Funicelli L, Travaini LL, Landoni F, Trifirò G, Bonello L and Bellomi M: Peritoneal carcinomatosis from ovarian cancer: the role of CT and [ $\left.{ }^{18} \mathrm{~F}\right]$ FDG-PET/CT: Abdom Imaging 35(6): 701707, 2010. PMID: 19784697. DOI: 10.1007/s00261-009-9578-8

10 Franko J, Shi Q, Goldman CD, Pockaj BA, Nelson GD, Goldberg RM, Pitot HC, Grothey A, Alberts SR and Sargent DJ: Treatment of colorectal peritoneal carcinomatosis with systemic chemotherapy: A pooled analysis of North Central Cancer Treatment Group phase III trials N9741 and N9841. J Clin Oncol 30(3): 2 63-267, 2012. PMID: 22162570. DOI: 10.1200/ JCO.2011.37.1039

11 Chua TC, Moran BJ, Sugarbaker PH, Levine EA, Glehen O, Gilly FN, Baratti D, Deraco M, Elias D, Sardi A, Liauw W, Yan TD, Barrios P, Gómez Portilla A, de Hingh IH, Ceelen WP, Pelz JO, Piso P, González-Moreno S, Van Der Speeten K and Morris DL: Early- and long-term outcome data of patients with pseudomyxoma peritonei from appendiceal origin treated by a strategy of cytoreductive surgery and hyperthermic intraperitoneal chemotherapy. J Clin Oncol 30(20): 2449-2456, 2012. PMID: 22614976. DOI: 10.1200/JCO.2011.39.7166

12 Sugarbaker PH: Peritonectomy procedures. Ann Surg 221(1): 2942, 1995. PMID: 14567026. DOI: 10.1016/s10553207(03)00048-6

13 Cashin PH, Graf W, Nygren P and Mahteme H: Cytoreductive surgery and intraperitoneal chemotherapy for colorectal peritoneal carcinomatosis: prognosis and treatment of recurrences in a cohort study. Eur J Surg Oncol 38: 509-515, 2012. PMID: 22475555. DOI: 10.1016/j.ejso.2012.03.001

14 Glehen O, Gilly FN, Boutitie F, Bereder JM, Quenet F, Sideris L, Mansvelt B, Lorimier G, Msika S and Elias D: Toward curative treatment of peritoneal carcinomatosis from nonovarian origin by cytoreductive surgery combined with perioperative intraperitoneal chemotherapy: A multi-institutional study of 1,290 patients. Cancer 116: 5608-5618, 2010. PMID: 2073757. DOI: $10.1002 /$ cncr.25356

15 Bray F, Ferlay J, Soerjomataram I, Siegel RL, Torre LA and Jemal A: Global cancer statistics 2018: GLOBOCAN estimates of incidence and mortality worldwide for 36 cancers in 185 countries. CA Cancer J Clin 68: 394-424, 2018. PMID: 30207593. DOI: $10.3322 /$ caac. 21492

16 Overman MJ, McDermott R, Leach JL, Lonardi S, Lenz HJ, Morse MA, Desai J, Hill A, Axelson M, Moss RA Goldberg MV, Cao ZA, Ledeine JM, Maglinte GA, Kopetz S and André T: Nivolumab in patients with metastatic DNA mismatch repairdeficient or microsatellite instability-high colorectal cancer (CheckMate 142): An open-label, multicentre, phase 2 study. Lancet Oncol 18: 1182-1191, 2017. PMID: 28734759. DOI: 10.1016/S1470-2045(17)30422-9
17 Huang CQ, Min Y, Wang SY, Yang XJ, Liu Y, Xiong B, Yonemura Y and Li Y: Cytoreductive surgery plus hyperthermic intraperitoneal chemotherapy improves survival for peritoneal carcinomatosis from colorectal cancer: A systematic review and meta-analysis of current evidence. Oncotarget 8: 55657-55683, 2017. PMID: 28903452. DOI: 10.18632/oncotarget.17497

18 Quenet F, Elias D, Roca L, Goere D, Ghouti L, Pocard M, Facy O, Arvieux C, Lorimier G, Pezet D, Marchal F J, Loi V, Meeus $\mathrm{P}$, De Forges H, Stanbury T, Paineau and Glehen O: A UNICANCER phase III trial of hyperthermic intra-peritoneal chemotherapy (HIPEC) for colorectal peritoneal carcinomatosis (PC): PRODIGE 7. J Clin Oncol 36: LBA3503-LBA3503, 2018. DOI: $10.1200 / \mathrm{JCO} .2018 .36 .18$

19 Sugarbaker PH: New standard of care for appendiceal epithelial neoplasms and pseudomyxoma peritonei syndrome? Lancet Oncol 7: 69-76, 2006. PMID: 16389186. DOI: 10.1016/S14702045(05)70539-8

20 Glehen O, Kwiatkowski F, Sugarbaker PH, Elias D, Levine EA, De Simone M, Barone R, Yonemura Y, Cavaliere F, Quenet F, Gutman M, Tentes AA, Lorimier G, Bernard JL, Bereder JM, Porcheron J, Gomez-Portilla A, Shen P, Deraco M and Rat P: Cytoreductive surgery combined with perioperative intraperitoneal chemotherapy for the management of peritoneal carcinomatosis from colorectal cancer: a multi-institutional study. J Clin Oncol 22: 3284-3292, 2004. PMID: 153107. DOI: 10.1200/JCO.2004.10.012

21 Vogel JD, Eskicioglu C, Weiser MR, Feingold DL and Steele SR: The American Society of Colon and Rectal surgeons clinical practice guidelines for the treatment of colon cancer. Dis Colon Rectum 60: 999-1017, 2017. PMID: 28891842. DOI: 10.1097/ DCR.0000000000000926

22 Van Cutsem E, Cervantes A, Adam R, Sobrero A, Van Krieken JH, Aderka D, Aranda Aguilar E, Bardelli A, Benson A, Bodoky G, Ciardiello F, D'Hoore A, Diaz-Rubio E, Douillard JY, Ducreux M, Falcone A, Grothey A, Gruenberger T, Haustermans K, Heinemann V, Hoff P, Köhne CH, Labianca R, Laurent-Puig P, Ma B, Maughan T, Muro K, Normanno N, Österlund P, Oyen WJ, Papamichael D, Pentheroudakis G, Pfeiffer P, Price TJ, Punt C, Ricke J, Roth A, Salazar R, Scheithauer W, Schmoll HJ, Tabernero J, Taïeb J, Tejpar S, Wasan H, Yoshino T, Zaanan A and Arnold D: ESMO consensus guidelines for the management of patients with metastatic colorectal cancer. Ann Oncol 27: 1386-1422, 2016. PMID: 27380959. DOI: 10.1093/annonc/ mdw235

23 Chua TC, Yan TD, Saxena A and Morris DL: Should the treatment of peritoneal carcinomatosis by cytoreductive surgery and hyperthermic intraperitoneal chemotherapy still be regarded as a highly morbid procedure? A systematic review of morbidity and mortality. Ann Surg 249: 900-907, 2009. PMID: 19474692. DOI: $10.1097 /$ SLA.0b013e3181a45d86

24 Franko J, Gusani NJ, Holtzman MP, Ahrendt SA, Jones HL, Zeh HJ $3^{\text {rd }}$ and Bartlett DL: Multivisceral resection does not affect morbidity and survival after cytoreductive surgery and chemoperfusion for carcinomatosis from colorectal cancer. Ann Surg Oncol 15: 3065-3072, 2009. PMID: 18712450. DOI: 10.1245/s10434-008-0105-x

25 Goéré D, Malka D, Tzanis D, Gava V, Boige V, Eveno C, Maggiori L, Dumont F, Ducreux M and Elias D: Is there a possibility of a cure in patients with colorectal peritoneal carcinomatosis amenable to complete cytoreductive surgery and 
intraperitoneal chemotherapy? Ann Surg 257: 1065-1071, 2013. PMID: 23299520. DOI: 10.1097/SLA.0b013e31827e9289

26 Kuijpers AM, Mirck B, Aalbers AG, Nienhuijs SW, de Hingh $\mathrm{IH}$, Wiezer MJ, van Ramshorst B, van Ginkel RJ, Havenga K, Bremers AJ, de Wilt JH, Te Velde EA and Verwaal VJ: Cytoreduction and HIPEC in the Netherlands: Nationwide longterm outcome following the Dutch protocol. Ann Surg Oncol 20: 4224-4230, 2013. PMID: 23897008. DOI: 10.1245/s10434-0133145-9

27 Elias D, Lefevre JH, Chevalier J, Brouquet A, Marchal F, Classe JM, Ferron G, Guilloit JM, Meeus P, Goéré D and Bonastre J: Complete cytoreductive surgery plus intraperitoneal chemohyperthermia with oxaliplatin for peritoneal carcinomatosis of colorectal origin. J Clin Oncol 27: 681-685, 2009. PMID: 19103728. DOI: $10.1200 / J C O .2008 .19 .7160$

28 Piso P, Stierstorfer K, Gerken M and Klinkhammer-Schalke M: Benefit of cytoreductive surgery combined with hyperthermic intraperitoneal chemotherapy in patients with isolated peritoneal metastases from colorectal cancer. Int J Colorectal Dis 33: 15591567, 2018. PMID: 30132068. DOI: 10.1007/s00384-018-3146-z
29 Elias D, Gilly F, Boutitie F, Quenet F, Bereder JM, Mansvelt B, Lorimier $\mathrm{G}$, Dubè $\mathrm{P}$ and Glehen $\mathrm{O}$ : Peritoneal colorectal carcinomatosis treated with surgery and perioperative intraperitoneal chemotherapy: retrospective analysis of 523 patients from a multicentric French study. J Clin Oncol 28: 6368, 2010. PMID: 19917863. DOI: 10.1200/JCO.2009.23.9285

30 de Cuba EM, Kwakman R, Knol DL, Bonjer HJ, Meijer GA and Te Velde EA: Cytoreductive surgery and HIPEC for peritoneal metastases combined with curative treatment of colorectal liver metastases: Systematic review of all literature and meta-analysis of observational studies. Cancer Treat Rev 39: 321-327, 2013. PMID: 23244778. DOI: 10.1016/j.ctrv.2012.11.003

Received March 25, 2020

Revised April 10, 2020

Accepted April 16, 2020 